\title{
ARTICLE
}

\section{Some thoughts about success fees for mediators}

\author{
Variations on the theme: 'The better it helps, the better it pays' \\ instead of 'The longer it takes, the better it pays'.
}

\author{
Patrick Van Leynseele
}

\section{Framework and general principles}

One of the basic principles of mediation, which is related to the notions of independence and neutrality, is that a mediator may have no interest at all in the outcome of the mediation. It must be neutral for him whether the mediation ends up in an agreement among the parties or not, or what type of solution emerges from the mediation. A 'solution', if any, is the parties' solution and decision, not that of the mediator. It may be influenced by multiple factors inherent to the (often contradictory) interests and needs of the parties. It will generally not be governed exclusively by the legal rules that would otherwise determine the outcome of the dispute in a court of law.

The logical consequence of that reasoning would be that the mediator may not have a personal financial interest in the outcome, for instance in the form of a higher fee in case of success than in case the mediation ends without an agreement (a contingency fee). Many codes of ethics have embodied that rule. The rule has even found its way in some legislation, such as the 'Directive on consumer ADR'. Its article 6.1(d) reads: 'Member States shall ensure that the natural persons in charge of $A D R$ possess the necessary expertise and are independent and impartial. This shall be guaranteed by ensuring that such persons: ... (d) are remunerated in a way that is not linked to the outcome of the procedure.' Section (34) of the introductory comments to the ADR Directive explains this rule by the need to provide for a system in which the neutral third party in charge of helping to solve the consumer dispute does not have 'any financial interest, direct or indirect, in the outcome of the ADR procedure. ${ }^{1}$

It is also quite common in the legislations that have implemented the EU Directive 52 of May 21, 2008 to have provided that the way the mediator's fees are to

1 Directive 2013/11/EU of the European Parliament and of the Council of 21 May 2013 on alternative dispute resolution for consumer disputes and amending Regulation (EC) No 2006/2004 and Directive 2009/22/EC, O.J. L 165/63 of 18.6.2013. In Belgium, the rule has been embodied in art. 2( $\left.7^{\circ}\right)$ of the Royal Decree of February 16, 2015 setting forth the conditions to which qualified entities (i.e. ADR entities for consumer disputes) must comply in order to satisfy the conditions of Book XVI of the Code of Economic Law. 
be determined must be spelled out in the mediation agreement signed among the parties and the mediator prior to the initiation of the mediation process. ${ }^{2}$

The way various existing rules of ethics have resolved the issue is to allow the mediator to charge only hourly fees or flat fees by half-day or by the day, but not to allow these fees to be higher in case the mediation ends with a solution than when no agreement is reached.

\section{The general prohibition is too broad}

Leaving aside the sector of consumer disputes to which specific legislation applies, one may question whether such rule is truly necessary and whether it is not too broad in its scope. What certainly counts the most is that the mediator should not be influenced in the way he acts by the fact that he would receive that higher pay in case of success. On its face, this could be the case if a success fee is provided for in the mediation agreement (or protocol as it is called in Belgium) i.e. the agreement among the parties and the mediator signed at the beginning of the process.

Practice, however, in particular in the commercial and trade area, shows that the parties do not necessarily object to the idea of paying contingency fees or success fees to a mediator when his intervention has allowed them to close the case with an agreement signed with the other side. On the contrary, parties may find that the mediator's fees, if limited to fees calculated on an hourly basis, may sometimes be abnormally low in comparison to the value they attribute to the mediator's intervention, which is what enabled them to reach an agreement with the other side, thereby avoiding litigation risks and expenses. Additionally, what the parties expect from the mediator at the outset of the mediation is that he will truly go out of his way as mediator; that he will use all his talents in order to allow the parties to reach a settlement. If that can lead to success, they may very well be willing to reward him more than if he tries to help the parties to find a solution, yet to no avail.

After all, this is what the parties have appointed him for!

In the same line of thinking, one may also question whether the mediator's remuneration calculated exclusively on the basis of time spent does not create a conflict of interest between the mediator and the parties to the extent that the mediator has no interest in the mediation being terminated too soon...

If one accepts the idea that success fees should not be prohibited altogether - thus changing the rule as it is traditionally taught and still is embodied in many standards or rules of ethics - a number of questions still arise, in particular about the acceptable limits:

2 E.g.: Czech Mediation Act 202/2012, sections 3(4) and 5(2)(d); Belgian code of civil procedure, art. $1731 \S 2,6$. 
1 Should the success or contingency fees, or the way to calculate them, necessarily be determined beforehand, i.e. at the time the mediation agreement is signed? Or can/should it be done later, for instance when an agreement among the parties has been reached?

2 What is 'success'? Is the simple fact that there is a settlement (or any type of agreement) enough, or should success be measured by one or another factor that constituted an element of the dispute (which may be analyzed differently by each party)?

3 Are there some types of 'success fees', or ways to calculate them, which must be prohibited altogether?

4 Who is to determine the amount/the level of the success fees if not spelled out entirely in the mediation agreement itself?

5 Who pays/shares the success fees? Could one imagine that the success fee is paid by one party and not by the other, with the significant risk that it be considered as some sort of 'greasing money' and a serious sign of infringement on the mediator's neutrality?

These questions are not all easy to solve. When trying to come up with an answer, one must bear some principles in mind: (i) the mediator may not be biased by the outcome of his intervention; (ii) it is not for him but for the parties to determine the acceptability, the nature and the 'level' of the solution, and (iii) the conditions of the mediator's intervention must be clear and transparent from the start.

\section{Combining mediators' and parties' interests}

In my eyes an acceptable solution would be to provide a scheme along the following lines:

a Rules of ethics and rules of mediation Institutes may allow success or contingency fees as a matter of principle under the following conditions.

b It is always for the parties to determine whether paying success fees is acceptable or not.

c When discussing the issue of contingency or success fees, the mediator is required to assess and discuss with the parties the possible consequences of such fee arrangements, including the appearance of, or actual loss of, his independence or neutrality.

d Some types of contingency fees should be prohibited altogether. Others are acceptable.

We will discuss each of these items shortly hereafter.

\section{a. Rules of ethics and mediation rules}

It used to be quite common to read in mediation rules or in rules of ethics that the mediator's remuneration could only be established on the basis of time spent. Things are changing, however. By way of example: 
- $\quad$ The 1994 Model Standards of Conduct for Mediators developed by the American Arbitration Association, the American Bar Association and the Association for Conflict Resolution prohibited success fees.

- When, in 2002, the CPR Institute in New York adopted its new Model Rule of Professional Conduct for Mediators, it dropped the prohibition altogether and imposed a double ethical duty on the mediator: (i) a duty to assess the possible conflicts arising out of the use of the fee arrangements, and whether the appearance or actuality of partiality prohibits its use under the Rules' principle of impartiality; and (ii) the mediator is required to disclose to the parties the possible consequences of the fee arrangements proposed. ${ }^{3}$

- When the 1994 Model Standard of Conduct for Mediators referred to above was amended in 2005, the same principles of the mediator's duties were integrated: a duty to provide complete information and a duty not to provide for fees in a manner impairing the mediator's impartiality. ${ }^{4}$

- When, in 2004, the European Commission adopted its European Code of Conduct for Mediators, it limited itself to providing for a duty of the mediators to always provide complete information as to the mode of remuneration they intend to apply. ${ }^{5}$ In other words, no prohibition of fees linked one way or the other to the outcome of the mediation process was imposed. Contract freedom prevails.

Since then, a number of mediation institutions have adopted rules that depart from the former total prohibition, setting forth certain limits however. ${ }^{6}$ We have no doubt in saying that others will follow.

\section{b. The parties must agree on success or contingency fees at the outset}

Mediators' fees are due under the mediation agreement entered into among them and the mediator prior to the initiation of the mediation process itself. There can be no doubt that the parties should determine themselves whether they agree to a scheme of remuneration of the mediator's work that is dependent upon a success-

3 Rule 4.5.6 'Fairness and Integrity of the Process'.

4 Standard VIII (A) and (B) 'Fees and other charges'. It is interesting to note that the Reporter's Notes to the new Model Standard dated April 10, 2005 only states the following reasons for amending the former prohibition rules: antitrust concerns raised by the flat prohibition on certain fee arrangements (which clearly includes the success fees prohibition) and concerns raised by the practice of unequal sharing of the mediator's fees among the parties.

5 Rule 1.3.

6 By way of example:

- The fee structure organized by the Milan Chamber of Commerce for its International Business Mediation service indicates that each party must make an advance payment of mediation fees, which include the flat mediation fee as such (determined on the basis of a schedule based on the amount at stake in the dispute) plus a $25 \%$ amount thereof as success fee. These $25 \%$ are to be reimbursed if the parties do not reach an agreement see: www.cameraarbitrale.it/Documenti/mediation-costs-sept2016.pdf.

- The International Maritime Conciliation and Mediation Panel has adopted rules calling for a 'success fee' equal to $100 \%$ of the total fee sum to become due in the event of a settlement of the dispute, whether or not such settlement is honored by the parties. 
ful outcome of the mediation. Any other rule would conflict with the statutory provisions calling for the fee arrangements to be established at the outset.

The difficulty lies more in the way the 'success fee' will be defined or determined: what do you measure it against? What is 'success'? Is the very existence of a settlement or other type of agreement reached at the mediation, as such, 'success'?

At the very least, the mediation agreement signed prior to the initiation of the process should contain the range and limits of the success fee and the way it ought to be calculated.

In any event, the 'trigger' for the success fee to apply should only be the fact that the mediation process has ended in an agreement signed between the parties.

\section{c. Full transparency}

The mediator is a professional in dispute resolution. It is up to him to make sure that the parties are aware of and understand the possible implications of success fees in the mediation process that they are embarking on. When discussing the issue of success fees, the mediator has a duty to assess and discuss with the parties the possible consequences of such fee arrangements, including the appearance or actual loss of his independence or neutrality: the fact that his pay is going to be higher in case of success might appear to be tantamount to a loss of neutrality and independence; a success fee based upon the amount of the settlement may be seen as giving him a personal interest in a settlement amount that is as high as possible, etc.

Although we believe that the (traditional) reasons to prohibit success fees are not all fully convincing, we have no doubt in saying that the parties must be guided by the mediator in becoming aware of the issues raised by the fee structure proposed by the mediator. Much as there are good enough reasons for a mediator to be rewarded better in case of a successful intervention, we believe that it is not too much to ask from the mediator to be fully transparent towards the parties on the issue. It is indeed sound to expect that the parties be put in a position in which they are able to give quality, explicit and informed consent to the fee structure. In addition, the mediator's candid comments on the fee structure he proposes will certainly enhance his credibility as a neutral and independent third-party in the eyes of the parties. To the contrary, his credibility will be undermined if, during the mediation process, there is an appearance of bias that the parties may feel is influenced by the fee structure if they were not fully informed beforehand.

\section{d. What types of success fees are acceptable?}

The rule that the mediator must have no stake in the outcome of the mediation is a sound rule per se. However, there are different categories of success fees. Not all of them should fall under the prohibited category because not all appear to detri- 
mentally influence the impartiality and neutrality of the mediator or the principle of self-determination of the parties. Some distinctions are in order: ${ }^{7}$

i 'Percentage of settlement': the mediator's fee is determined by the percentage of the settlement amount. This should remain prohibited because it creates an interest for the mediator to push for the highest amount possible. Such contingency fee can only be appropriate for the lawyer of the plaintiff; not for a neutral mediator.

ii Pure 'success fee': such fee (a higher hourly fee or a fixed, lump sum amount) is contingent only on the parties reaching a settlement, whatever its nature or contours. ${ }^{8}$

iii 'Percentage of costs saved': the additional fee equals a percentage of the estimated cost savings as compared to a judicial process.

iv 'Percentage of value created': the mediator's additional fee corresponds to a percentage of the 'additional value' created through the mediation process, i.e. the value of the 'increased pie'.

We believe that models (ii) through (iv) are acceptable. Admittedly, they may create bias (or an appearance of bias) towards settlement - the mediator is no longer fully neutral as to whether the dispute reaches settlement or not - or in the conduct of the process - the mediator is no longer fully neutral as to the type of settlement reached. However, that does not undermine the mediator's core function, which is to remain neutral and independent towards each party. To the contrary, the mediator's own interest is aligned with that of the parties, which is to join forces and work together in order to reach a settlement.

For models (iii) and (iv) there may be a difficulty in defining 'costs saved' or 'value created' at the outset, that is when the details of the disputes and of the parties' situation is not known to the mediator yet. In our view, it should be sufficient to define the principle in the mediation agreement - it must be done in order to comply with the statutory requirements - and to leave it to the parties and the mediator to accurately define in the course, or at the end of the mediation process, the amounts to which the agreed percentage must be applied. That leaves a margin of uncertainty, but it also provides a measure of flexibility, which the parties and the mediator ought to be able to discuss when the mediation process has yielded a settlement. Expressed differently: the mediation agreement may be limited to providing a framework for the calculation of the success fee, and the parties and the mediator should be allowed to determine its precise amount together once the dispute among the parties has been settled.

Mediation rules and mediation institutions' rules for the remuneration of mediators or rules of ethics should draw the lines of what is acceptable and what is not.

7 We may refer to an insightful article of Scott Pepett, Contractarian economics and mediation ethics: the case for customizing neutrality through contingent fee mediation, Texas Law Rev., Vol. 82, Nb. 2, December 2003, 227.

8 This is the model adopted by the Milan Chamber of Commerce and the International Maritime Conciliation and Mediation Panel referred to above. However, we understand that the success fee portion is kept by the Chamber and is not paid to the mediator himself. 


\section{In what type of mediations?}

One may wonder whether a system of success fees is appropriate in just any kind of mediation.

In our view, it certainly is appropriate in business disputes: experience teaches that a system of better pay depending on value added (as a result of the mediator's intervention) often comes as a request from the parties themselves.

Arguably, the same should be true for any type of mediation, with the evident exclusion of mediations for which there is a statutory prohibition such as consumer disputes.

In family matters, where the emotional aspects often play a central role in the dispute, linking the remuneration of the mediator to the very fact that a final solution has been found, may perhaps be less appropriate. Indeed, in that type of disputes, the financial aspects - and, hence, the notion of 'value added' - may be less relevant or appropriate.

\section{Conclusion}

Success fees for mediators are not as anathema as one used to think. There is nothing shocking in setting up a framework for the remuneration of mediators that is built upon a remuneration system that is more favorable when the work performed has resulted in the success that the parties were hoping for, i.e. a mediated settlement. One should, however, provide for a duty of the mediator to be fully transparent at the outset in the method of calculation of the fees he is suggesting, as well as about all the consequences - including appearance of bias that the scheme entails. This, by the way, is nothing new since the principle already exists in most rules of ethics or standards of conduct to do just that: provide clarity about the remuneration system.

The (only) trap to be avoided is to render the mediator's interests contrary to those of the parties or one of them. The success or contingency fee structure may not compromise the mediator's all important neutrality and independence towards the parties.

If the mediator's interests correspond to those of the parties, why not reward him better in case of settlement? After all, if any work deserves reasonable pay, good work deserves better pay. Or does it not? 